Teaching and Learning (2009) 5(1), 53-62

\title{
Ready or Not, Here They Come: Inclusion of Invisible Disabilities in Post-Secondary Education
}

\author{
KAREN CSOLI \\ Brock University \\ SHEILA BENNETT \\ Brock University \\ TIFFANY L. GALLAGHER \\ Brock University
}

\begin{abstract}
In Ontario, elementary and secondary school programs such as "School Success" and legislation such as Education for All have greatly increased the success of students with disabilities. Success at the secondary school level means that more students with disabilities are choosing to attend postsecondary institutions. This paper focuses on the transition of students with invisible disabilities from secondary to post-secondary education. Universal Instructional Design is reviewed as an appropriate teaching tool for the postsecondary level, as it allows for increased access to meaningful learning experiences for students with and without disabilities. At this point in time, rights-based inclusion is still a novel concept and post-secondary educators struggle with what it means and what it looks like to include learners with disabilities. Issues that prevent the rights of individuals with special needs from being realized include access to higher education, limited funding, and employment equity.
\end{abstract}

The inclusion of students with special needs in mainstream educational settings has become commonplace within the province of Ontario, as well as across the country. The Ministry of Education for the province of Ontario (Statistics Canada, 2006) reports that approximately $85 \%$ of students identified as having a disability are included in regular classes for more than fifty percent of the day. While there is still progress to be made, genuine inclusion of students with disabilities in our classrooms is observable. Genuine inclusion rejects the perception that students with disabilities are the other, which is in contrast with what should be the ultimate goal of educators and educational institutions (McPhail \& Freeman, 2005). 
Ready or Not, Here They Come: Inclusion of Invisible Disabilities in Post-Secondary Education

Recently, there has been a focus on enhancements to inclusion at the secondary school level, and attention has also been directed to supporting learners that pursue postsecondary education. Additional supports for educators and students have been put into place to ensure successful learning outcomes. Examples include programs such as "School Success," which focuses on students at risk, extensive professional development in differentiated instruction, and an expansion of the support document, Education for All (Ontario Ministry of Education, 2005) that will include instructional guidelines for students at the secondary level. With an increased concentration on successful school completion and the provision of high quality modification and accommodation at the secondary level, the natural progression of student learning is to propel them into postsecondary institutions to pursue their educational and career goals. The transition into post-secondary educational institutions for students, in particular those with learning disabilities, is the focus of this paper. The paper will also focus on the application of Universal Design for Instruction (McGuire, Scott, \& Shaw, 2006) as a valuable and viable option for post-secondary level learners.

\section{The Current State of Affairs}

In a recent survey, $14.3 \%$ of Canadians reported having a disability that affected their ability to perform everyday activities (Statistics Canada, 2006). This includes access to university programs which continues to be problematic for students with disabilities, as does retention within programs, once accepted (Getzel, 2008; Pliner \& Johnson, 2004). In fact, Statistics Canada (2006) reported that from the approximately 4.2 million Canadians with disabilities in 2006, many do not have equal participation in higher education and subsequent access to higher levels of employment and income. In terms of employment, Statistics Canada (2006) also reported the average annual income of persons with disabilities ages 15 to 64 is $\$ 28,503$ (median $\$ 19,199$ ), while the average annual income for persons without disabilities is \$37,309 (median \$27,496). Further data from 2001 revealed that the percentage of Canadians attaining at least a high school education is $74.7 \%$, while the percentage of persons with disabilities attaining a high school diploma is $62.9 \%$ (Statistics Canada, 2003). While $20.3 \%$ of persons without disabilities in 
Ready or Not, Here They Come: Inclusion of Invisible Disabilities in Post-Secondary Education

Canada have attained university education, only $11.4 \%$ of persons with disabilities have done the same (Statistics Canada, 2003).

As elementary and secondary schools continue to seek ways in which the provision of educational opportunities for all students can be enhanced at the postsecondary level, providing modifications and accommodations for students with disabilities, in particular those with learning disabilities, is a relatively recent undertaking. The inclusion of persons with disabilities into the complex and varied learning opportunities offered at the post-secondary level presents both challenges and potential prospects.

\section{Persons with Disabilities at the Post-Secondary Level}

For a number of years, post-secondary institutions have worked to include persons with visible disabilities (e.g., physical disabilities, visual impairments) into educational contexts. Human rights legislation (e.g., Canadian Charter of Rights and Freedoms, 1982; Convention on the Rights of the Child, 1989), advocacy (e.g., World Programme of Action Concerning Disabled Persons, 1982), and a sense of moral righteousness have propelled post-secondary institutions, as well as the larger community, to make buildings accessible and provide augmentative communication tools. While many challenges still exist, an additional complexity has emerged as a function of the increased support provided at the elementary and secondary school levels for students with cognitive and emotional disabilities. For these students with invisible disabilities (e.g., learning disabilities), accurate assessment and identification, disclosure issues and attitudinal barriers are at the forefront when considering how best to deliver effective programming within post-secondary institutions (Grabinger, Aplin, \& Ponnappa-Brenner, 2008; Pliner \& Johnson, 2004).

\section{Admissions}

Post-secondary institutions are cognizant of the fact that a disability may have an effect on a secondary school applicant's academic achievement. In Ontario, universities and colleges independently set accessibility admissions policies in consultation with appropriate professional bodies and the Ontario Human Rights Commission. These 
Ready or Not, Here They Come: Inclusion of Invisible Disabilities in Post-Secondary Education

policies provide an opportunity for students experiencing 'special circumstances' that may have impacted their secondary school marks (e.g., a recently diagnosed disability), to receive equal consideration for entrance to post-secondary education. Standard application procedures dictate that Canadian citizens or permanent residents with a disability may submit additional supporting documentation as specified by the institutions. By doing so, candidates are ensured that their applications are reviewed individually and decisions regarding their admissions are determined on a case-by-case basis. The accessibility policy is not considered a modified admission as each applicant must still meet the minimum program requirements.

Policies for students experiencing 'special circumstances' do not exist at the graduate level, however. Students with disabilities are not required to submit additional supporting documentation that may explain, for example, lower marks. Self-disclosure remains a sensitive topic and is employed on a limited basis. Due to the competitive nature of acceptance into graduate programs, applicants with disabilities often do not want to risk jeopardizing their acceptance by appearing to have a handicap. Graduate admissions personnel might assume that a student with a disability must have received an equitable opportunity to achieve high grades, and if grades do not meet a set standard, the student might not have been able to overcome the barriers to success in higher education. While there may have indeed been personal issues impeding success, this does not allow for consideration of the possible barriers created by the educational context, such as lack of appropriate technology and universal instructional practices at the post-secondary level.

\section{Current Practices}

Unlike elementary and secondary schools where educators have access to information about their students with disabilities, students at the post-secondary level have their diagnosis and documentation protected by confidentiality protocols. Most institutions have an independent office for students with disabilities, whose role is to act both as an agent of the institution and as an advocate for the student. These offices request appropriate documentation of a diagnosis of a disability that includes additional information on the educational impact of the disability. Only members of the disability 
Ready or Not, Here They Come: Inclusion of Invisible Disabilities in Post-Secondary Education

office are permitted access to this confidential information. Course instructors are notified, usually by letter, that a particular individual has been identified as a student with a disability, and instructors are also provided with a list of requested accommodations.

Post-secondary students with disabilities can receive appropriate and individualized accommodations, such as a note-taker, but they cannot receive a modified curriculum. This means that all students are expected to demonstrate an appropriate understanding of the core course objectives as determined by the course instructor. Accommodations such as extra time on tests or access to assistive software for assignments and exams are intended to assist students while they learn and demonstrate their understanding of the course content.

Many disabilities, such as learning disabilities, affect the time it takes a student to read, research, write, or process information. This often requires students with disabilities to take a reduced course load and to have flexibility with due dates. These students may also require alternate formats for their textbooks to allow text-to-voice software to read text out loud. Using alternate technologies also requires extra time to scan texts, dictate information, or frequent breaks due to visual fatigue. A reduced course load may result in extended time needed to complete a program, thus increasing the cost of university and delaying entry to the workforce. How can post-secondary level educators stream-line the learning process for students with learning disabilities?

\section{Enhanced Services for Students with Learning Disabilities}

Over the past eight years, the inclusion of students with learning disabilities in post-secondary level institutions, and access to individualized supports for them, has changed dramatically. In 2006, approximately 631,000 (2.5\%) of adults (aged 15 years and older) with a disability reported having a learning disability. By contrast, $89.6 \%$ of children (aged 5 to 14 years) with a disability reported having a learning disability (Statistics Canada, 2006). In 2006, 33.7\% of the people with a learning disability had an education beyond a high school diploma (Statistics Canada, 2006). With increased testing and identification at the elementary and secondary school levels, the number of adults reporting a learning disability is likely to continue to increase and impact the provision of support services at the post-secondary level. 
Ready or Not, Here They Come: Inclusion of Invisible Disabilities in Post-Secondary Education

In the late 1990s, the increased enrolment of adults with learning disabilities into post-secondary level programs was anticipated. It was during this time that The Learning Opportunities Task Force (Ministry of Training, Colleges and Universities, Government of Ontario, 2002-2003) was given the mandate to research best practices that support students with learning disabilities at the college and university levels. After several years of pilot projects and research, it was determined that post-secondary level students with learning disabilities need support in two areas: study strategies and assistive technology. This is consistent with current research (e.g., Baker, Gersten \& Graham, 2003; Goldberg, Higgins, Raskind, \& Herman, 2003; Mortimore \& Crozier, 2006) that has linked success for students with learning disabilities in post-secondary education to supports such as focused training in study and coping strategies.

In 2002, the Ontario Ministry of Training, Colleges, and Universities gave funding to post-secondary institutions to provide enhanced services in the form of Learning Strategists and Assistive Technologists. These staff members work one-on-one with students to improve study skills and to assist students with the use of assistive technology. It is important to note, however, that Enhanced Services Funding is not basic funding nor is it expected to be a mandatory service provided by the universities.

Having said this, the mandate of the Enhanced Services Funding includes outreach to the institutional community. Yet the experience of many post-secondary institutions is that demand for academic support and assistive technology is so high, that there is a waiting list for direct student services. This leaves little time to develop connections and partnerships that increase the institution's knowledge of the needs of students with learning disabilities. Since Enhanced Services is limited to those with learning disabilities, students with other invisible disabilities, such as mental health conditions, are not eligible to receive support, nor do they have an alternative funding package. While an important support for students with learning disabilities, this program does not offer much in the way of support for faculty in their attempt to understand and teach students with learning disabilities that are entering their courses in increasing numbers. 
Ready or Not, Here They Come: Inclusion of Invisible Disabilities in Post-Secondary Education

\section{Provision of Services: Universal Design for Learning}

Universal Design (UD) initially was conceived within an architectural context. Designing spaces for maximum usability by individuals without the need for specialized adaptations became the focus for UD. Building on this concept of universal access, the notion of Universal Design for Learning (UDL) emerged. As with UD, the focus of UDL is to reconceptualize the design of learning opportunities to ensure the development and delivery of curriculum with inclusiveness at the start and throughout rather than as an add-on. Universal Design for Instruction (UDI) builds on the concept of UDL and offers a specific focus for post-secondary level of education with regard to students with disabilities such as learning disabilities (McGuire, Scott, \& Shaw, 2006; Scott, McGuire, \& Shaw, 2003; Pliner \& Johnson, 2004). Using the principles of UDI can provide students with learning disabilities easier access to course materials, thus reducing the amount of time needed to make the material accessible.

While UD and UDL are an integral part of the types of learning environments that can be found across the wide spectrum of services provided to students from primary to post-secondary levels of education, the introduction of UDI brings specific focus to invisible disabilities at the post-secondary level. McGuire, Scott and Shaw (2006) provide nine primary principles for implementing UDI: equitable use, flexibility in use, simple and intuitive, perceptible information, tolerance for error, low physical effort, size and space for approach and use, a community of learners, and instructional climate.

Each of these principles has been delineated into an operational definition within a university context (Scott, McGuire, \& Shaw, 2003; McGuire, Scott, \& Shaw, 2006). The first principle, 'equitable use,' refers to the need for the design of any instructional materials to be accessible to students with diverse needs. Post-secondary instructors should ask: Can the information be easily obtained, and utilized by the student? The second principle, 'flexibility in use,' should entail a straightforward instructional approach with a variety of methods that allow for different types of learners. "Simple and intuitive" instruction ensures that instructors design instruction in a straightforward way in which nothing is implied or ambiguous. "Perceptible information" requires the instructor to respect and respond to the different learning styles and abilities of their students by taking into account their diverse needs. Principle five allows for 'tolerance 
Ready or Not, Here They Come: Inclusion of Invisible Disabilities in Post-Secondary Education

for error,' in which students are offered consistent feedback and the provision of additional opportunities for demonstrating growth. Principles six and seven, 'low physical effort' and 'size and space for approach and use' address such issues as: mobility, physical exertion, efficiency and communication limitations. The development and maintenance of a "community of learners" is described in principle eight. Within this principle, consideration needs to be given to the provision of opportunities for productive communication between students, as well as between instructors and students. The final principle, 'instructional climate,' refers to the building of an environment that respects diversity and is designed to be inclusive. This delineation has been further refined within an Ontario context through The Learning Opportunities Task Force (Ministry of Training, Colleges and Universities, Government of Ontario, 2002-2003), which created an implementation guide for university and college instructors to cultivate their teaching within the context of UDI. While the adoption of the practices recommended in this manual are voluntary, they do serve as a vantage point from which to view the possibilities for post-secondary instructional delivery.

\section{Challenges and Concluding Thoughts}

It would seem that despite progress over the last decade, the real challenge for post-secondary institutions is not one of modification for students with disabilities, but rather of creating a paradigm shift. International, national, and provincial movements focused on the full and functional inclusion of individuals with disabilities into mainstream education and society are evidence of a changing mindset regarding the value of persons with special needs. Demonstrative approximations of genuine inclusion have taken much time to attain. Yet, the paradigm shift from charity-based approaches to inclusion, to rights-based approaches to inclusion, is becoming evident at every level of government throughout the world (Kuno, 2009). This has not always been the case at universities, perhaps because of a historically exclusionary nature.

At this point in time, rights-based inclusion is still a novel concept, and postsecondary educators continue to struggle with what it means and what it looks like to include learners with disabilities. We need to address the issues which prevent the rights of individuals with special needs from being realized, such as access to higher education, 
Ready or Not, Here They Come: Inclusion of Invisible Disabilities in Post-Secondary Education

limited funding, and employment equity. A genuinely inclusive society will be one step closer when education systems successfully overcome these issues. Even though progress has been made in admissions for undergraduate students with disabilities, there still exist barriers to the pursuit of graduate degrees. The accommodation of students with visible disabilities continues to result in architectural, acoustic, mobility, and sensory challenges, to name a few. The additional challenge of including students with invisible disabilities, such as learning disabilities, requires more discussion.

Following the principles outlined in UDI does allow for more access to meaningful learning experiences at the post-secondary level, for students with and without disabilities. As with any type of universal design, the intent is not to provide access for a few, but for all. Every student in any educational environment would benefit from feedback, respectful space, learning styles consideration, community building, and collaboration. While UDI has been a catalyst for a re-examination of how curriculum is designed and delivered for students within post-secondary institutions, it has also heightened awareness and a sense of responsibility for assisting students with disabilities. Continuation along this path of progress will likely result in enhanced and more meaningful instruction for all.

\section{References}

Baker, S. Gersten, R., \& Graham, S. (2003). Teaching expressive writing to students with learning disabilities: Research-based applications and examples. Journal of Learning Disabilities, 36(2), 109-123.

Canadian Charter of Rights and Freedoms, Schedule B, Constitution Act, 1982. Convention on the Rights of the Child (1989). United Nations General Assembly Resolution 44/25.

Getzel, E. (2008). Addressing the persistence and retention of students with disabilities in higher education: Incorporating key strategies and supports on campus. Exceptionality, 12, 207-219.

Goldberg, R. J., Higgins, E. L., Raskind, M. H., \& Herman, K. L. (2003). Predictors of success in individuals with learning disabilities: A qualitative analysis of a 20year longitudinal study. Learning Disabilities Research and Practice, 18(4), 222236.

Grabinger, R. S., Aplin, C. \& Ponnappa-Brenner, G. (2008). Supporting learners with cognitive impairments in online environments. TechTrends: Linking Research and Practice to Improve Learning, 52(1), 63-69. 
Ready or Not, Here They Come: Inclusion of Invisible Disabilities in Post-Secondary Education

Kuno, K. (2009). Disability equality training (DET): Potentials and challenges in practice in developing countries. Asia Pacific Disability Rehabilitation Journal, 20(1).

Retrieved on March 26, 2009 from: http://www.dinf.ne.jp/doc/english/asia/resource/apdrj/vol20 $1 /$ developmental$\underline{\operatorname{art} 2 . h t m l}$

Ministry of Education, Government of Ontario (2005). Education for all: The report of the expert panel on literacy and numeracy instruction for students with special needs, Kindergarten to Grade 6. Toronto: Queen's Printer for Ontario.

Ministry of Training Colleges and Universities, Government of Ontario (2002-2003). The learning opportunities task force.

McGuire, J., Scott, S., \& Shaw S. (2006). Universal design and its application in educational environments. Remedial and Special Education, 27(3), 166-175.

McPhail, J. C. \& Freeman, J. G. (2005). Beyond prejudice: Thinking toward genuine inclusion. Learning Disabilities Research \& Practice, 20(4), 254-267.

Mortimore, T., \& Crozier, W. R. (2006). Dyslexia and difficulties with study skills in higher education. Studies in Higher Education, 31(2), 235-251.

Pliner, S. \& Johnson, J. (2004). Historical, theoretical, and foundational principles of universal instructional design in higher education. Equity and Excellence in Education, 37, 105-113.

Scott, S., McGuire, J., \& Shaw, S. (2003). Universal design for instruction: A new paradigm for adult instruction in postsecondary education. Remedial and Special Education, 24(6), 369-379.

Statistics Canada (2003). Education, employment and income of adults with and without disabilities - tables: 2001 Participation and activity limitation survey. Minister of Industry, Catalogue No. 89-587-XIE.

Statistics Canada (2006). The 2006 Participation and Activity Limitation Survey: Disability in Canada, Catalogue No. 89-628-XWE.

World Programme of Action Concerning Disabled Persons (1982). United Nations document A/37/51, Official Records of the General Assembly, Thirty-seventh Session Supplement No. 5. 